\title{
"It's Not a Cookie-Cutter Scenario Anymore": the COVID-19 Pandemic and Transitioning to Virtual Work
}

\author{
Lisa Klein Vogel $^{1}$ (D) $\cdot$ Vee Yeo ${ }^{1}$
}

Accepted: 19 February 2022 / Published online: 1 March 2022

(c) The Author(s), under exclusive licence to Springer Nature Switzerland AG 2022

\begin{abstract}
The COVID-19 pandemic forced human services agencies, including child support agencies, to find ways to continue providing services. Many agencies considered changes to where and how staff work, in addition to new modalities for service provision. This paper explores how five Wisconsin child support agencies approached staff work arrangements and service delivery during the pandemic; challenges and opportunities encountered; changes agencies expect to persist; and implications for policy and practice. Data were gathered through semi-structured interviews with child support directors and staff in five Wisconsin counties between January and February, 2021. Data were analyzed thematically. Despite limited information and little prior experience working virtually, county agencies rapidly adapted staff work arrangements and service delivery methods to facilitate service continuity. Strategies used by agencies varied across counties, given local directives, resources, and constraints, and as the pandemic evolved. Despite variation, counties contended with a similar array of decision points, including changes to physical spaces, office closures, and staff work locations. Agencies also implemented creative strategies to connect with customers and keep services accessible. Findings suggest that innovative combinations of traditional and newer methods can help agencies maximize reach. Further, the infrastructure and experiences counties gained by working in new ways offer increased flexibility and improved capacity for service continuity in the future. Policymakers could support these efforts by providing guidance related to confidentiality and data security; supporting and facilitating crisis contingency planning; coordinating information exchanges; procuring technology and resources; and advocating for infrastructure, particularly broadband internet.
\end{abstract}

Keywords Human services program operations · Child support program · COVID19 pandemic $\cdot$ Virtual service delivery $\cdot$ Telework arrangements

Lisa Klein Vogel

lmklein@wisc.edu

1 Institute for Research on Poverty, University of Wisconsin-Madison, 1180 Observatory Drive, WI 53706 Madison, USA 


\section{Introduction}

On March 11, 2020, the World Health Organization declared the rapidly spreading coronavirus 2019 disease (COVID-19) a global pandemic (World Health Organization, 2020). Since then, the COVID-19 pandemic has dramatically affected public health, economic, and social conditions worldwide. As of February 14, 2022, the USA had recorded over 77.7 million COVID-19 cases and nearly 920,000 deaths due to COVID19. Over 1.5 million cases and 12,800 of these deaths have occurred in Wisconsin, the site of this study (Johns Hopkins University \& Medicine, 2022). As the pandemic unfolded, nationally and in Wisconsin, changing public health conditions and a series of public health orders forced human services agencies consider whether and how to provide services to child support customers (i.e., custodial parents, or CPs, and noncustodial parents, or NCPs) in new ways. With little time to prepare, agencies needed to make decisions with important consequences for customer and staff safety; the ability of customers to access information and help in a period of great uncertainty and economic hardship; and the well-being of a workforce experiencing significant changes in life and work. Leaders had to make these decisions with limited information and in local health and operational contexts that varied substantially.

The COVID-19 pandemic has illuminated the potential for public health or other emergencies to demand rapid changes to where and how human services staff work and has also provided important insights into how public-facing agencies can continue to serve customers in need when conditions make traditional means difficult. Despite the importance of understanding human services agency adaptations and future plans, particularly given the pandemic's persistence, research on this topic is limited and emergent. This study aims to help address this gap by examining the experiences and perspectives of one type of human services agencies-child support agencies - in Wisconsin as they navigated staffing and service delivery changes early in the pandemic. Drawing on interviews with child support agency leadership and frontline staff, we explore the following four research questions:

1. How did child support agencies adapt: (a) physical spaces, (b) staff work arrangements, and (c) service delivery in response to the COVID-19 pandemic, and what factors drove these changes?

2. What challenges and opportunities did agencies encounter as they modified their staffing and services?

3. What lessons have agencies learned in making these adaptations?

4. To what extent do agencies expect changes staffing and service delivery to persist in the future? 


\section{Background and Policy Context}

\section{The Role of Child Support}

Child support agencies play an important role in the economic well-being of many families. Most children in the US children will spend some or all of their childhood living apart from a parent (Andersson et al., 2017), and in 2019, the child support program collected over 34 billion dollars in payments on behalf of over 14 million children nationally (Office of Child Support Enforcement, 2019). The child support program seeks to ensure that parents living apart from their children contribute to their financial well-being, while also aiming to reduce public expenditures for welfare programs (Committee on Ways and Means, 2018). Particularly in the face of significant cuts to programs that provide cash assistance to low-income people, child support plays an important role in reducing childhood poverty (Cuesta \& Meyer, 2018; Sorensen, 2010).

\section{The Wisconsin Child Support Context}

In Wisconsin, the child support program is supervised by the state and administered locally by 71 counties and 9 tribes. The state oversees the program; develops policy; provides technical assistance and training; monitors compliance with federal and state guidelines; collects and distributes payments; and supports enforcement through centralized locating and matching services and the lien docket. County agencies are responsible for enacting policy and operating local programs. They establish paternity and set and enforce orders for financial and medical support. County agencies must operate within state and federal guidelines but are able to interpret and implement policy within their local contexts (Gentry, 2017), which vary considerably across counties. For example, Wisconsin counties vary in geographic size, rurality, population size, and economic wellbeing (U.S. Census Bureau, 2021), as well as child support caseload size, ranging from as low as 219 cases in Florence County, Wisconsin, to 123,000 in Milwaukee County, Wisconsin, in 2019 (Wisconsin Department of Children \& Families, 2021d).

Within Wisconsin counties, child support agencies and the courts both play important roles in child support functions and operations. Agencies coordinate genetic testing; perform locate services; prepare paperwork for child supportrelated court actions; review orders; take administrative enforcement actions such as license suspension and asset seizure; and provide financial services, such as coordinating automatic income withholding with employers (Gentry, 2017; Wisconsin Department of Children \& Families, 2021a). In some counties, staff perform all services for a given case, from origination through closure; in others, staff specialize by function (Vogel, 2021). Child support orders are set via court order, and all order modifications, including stipulated agreements, must be approved by courts (Gentry, 2017; Wisconsin Department of Children \& 
Families, 2021b). In Wisconsin and more broadly, child support agencies and courts collaborate with local law enforcement to enforce court orders through civil contempt proceedings (Cook \& Noyes, 2011; Gentry, 2017) and to facilitate cooperation with court proceedings, such as paternity establishment (Cook, 2012; Wisconsin Department of Children \& Families, 2021c). Therefore, the ability of child support agencies to perform essential functions depends in part on these legal system actors, and circumstances that affect legal partners have the potential to affect child support agency operations.

\section{Literature: Virtual Service Provision}

Prior to the COVID-19 pandemic, some fields had already started to incorporate virtual approaches to service delivery. Within the telehealth literature, a number of pre-pandemic studies demonstrated promising applications of virtual service options across a number of subfields, such as general practice telehealth consults (Hah \& Goldin, 2019; Newman et al., 2016), virtual provider visits with older adults (Husebø \& Storm, 2014), and video-based psychological services (Fogler et al., 2020). Though evidence is limited, several pilot studies within human services also demonstrate potential benefits. Examples include pilot parenting interventions that use texting (Bigelow et al., 2008; Snell et al., 2020) and virtual home visiting programs (Mogil et al., 2015; National Home Visiting Resource Center, 2017). Virtual options have the potential to reach customers who live outside of service areas (including rural areas, if internet services are available), who move frequently, and who are not receptive to in-home visits (Hirko et al., 2020; National Home Visiting Resource Center, 2017; Nilson, 2017; Semanchin-Jones, 2011), and can help overcome other barriers to face-to-face service offerings, such as transportation issues, childcare barriers, anxiety, and other mental health difficulties. They can also help agencies offer a broader array of services, connect with customers more frequently, and potentially improve information-sharing between providers and customers (Cook \& Doyle, 2002; Mogil et al., 2015; National Home Visiting Resource Center, 2017; Semanchin-Jones, 2011). Some studies have found high levels of satisfaction with virtual services among staff and customers (Bigelow et al., 2008; Finn \& Schoech, 2008; Finn et al., 2004), particularly among younger populations (Alford et al., 2019; Hetling et al., 2014; Lenhart et al., 2005).

Despite the promise virtual service offerings hold, they also come with tradeoffs and limitations, particularly for services that are paperwork-intensive or involve legal proceedings. Serving customers virtually raises a host of concerns about information security, confidentiality, and legal and ethical issues (Zack, 2008). Some evidence suggests that offering services in virtual formats can require significant effort on the part of providers (Fogler et al., 2020; Rosen et al., 2021) and can make it difficult to assess client needs accurately (Bambling et al., 2008). Additionally, technology itself can create difficulties; when it does not work as intended, such as due to connection quality or technology constraints, these problems can create frustration and technology avoidance (Hah \& Goldin, 2019; Kelso et al., 2009; Rosen et al., 2021). Some evidence has also found that while some customers enjoy virtual 
options, others prefer face-to-face interactions (Fogler et al., 2020). Further, the aforementioned issues related to technology and broadband access, particularly for rural and low-income customers, raise practical difficulties for reaching many clients and ethical concerns about access inequities (Zack, 2008).

We are still learning how institutions adapted to new ways of working during the pandemic, and much remains unknown. Information on child support agencies specifically is scant, though group discussions with child support directors convened by the National Child Support Enforcement Association (NCSEA) (Future of Child Support, 2020) offer helpful insights. Directors reported continuity of many service functions despite many offices closing and staff often working remotely, though paternity establishment processes were especially prone to delays due to disruptions in court processes and genetic testing. Directors reported challenges to transitioning to virtual services, including outdated technology, limited staff telework experience, court closures, and printing and mailing materials. Overall, however, they reported optimism about the future of virtual work and noted positive resultant program changes, including technology modernization, revisiting in-person requirements, new communication tools for staff and customers, and expanded service hours (The Future of Child Support, 2020).

Within human services agencies broadly, a small body of early evidence drawing on research with human services providers during the COVID-19 pandemic suggests that incorporating virtual offerings helped some programs to maintain customer relationships, reach customers with in-person access barriers (Emezue, 2020; Mishna et al., 2020; Oehme et al., 2021), meet with clients more often, and maintain more consistent engagement (Cruden et al., 2021; Font, 2021; Oehme et al., 2021). Additional insights come from federally commissioned qualitative interviews and focus groups with human services providers and customers, which found that for some customers, virtual platforms improved staff responsiveness and ease of access to staff, reduced administrative burden, and mitigated barriers such as transportation and child care (Benton et al., 2021a). Staff described increased frequency of communication and group participation through virtual platforms, but also reduced opportunities for building rapport (Benton et al., 2021b). However, customers also reported downsides to virtual services, such as problems with internet connectivity and speeds, and customer preferences for service modality were mixed (Benton et al., 2021a). Staff noted that virtual service offerings work especially well for populations with certain barriers, such as child care, transportation, distance, or health concerns, and for people comfortable with technology, but characterized in-person services as often preferable for people with technology limitations, intellectual disabilities, language barriers, in immediate crisis, and older adults and young children (Benton et al., 2021c).

\section{Internet Access in Wisconsin}

The ability to access the internet, a necessary precondition for accessing some virtual services, varies based on where Wisconsinites live and their financial circumstances. Access to the internet is strongly correlated with population density and 
income (Conroy et al., 2021; Reddick et al., 2020). Wisconsin lags nationally in access to reliable broadband (or "high-speed") internet (Knapp \& Votava, 2020), though access varies across and within counties; only $63 \%$ of Wisconsin's rural residents have access to broadband, compared to $95 \%$ in urban areas. In many rural areas, satellite internet connections, which are slower, more costly, more easily weather-affected, and offer more limited data allotments, are the only option. Access is also a problem for low-income households in urban and rural areas. Of Wisconsin households with annual earnings under $\$ 20,000,44 \%$ of urban households and $56 \%$ of rural households have no internet access of any kind (Conroy et al., 2021; Jones \& Ewald, 2017).

\section{The COVID-19 Pandemic in Wisconsin}

Immediately following the WHO's declaration of the COVID-19 disease as a global pandemic, the Wisconsin state government began enacting public health measures. On March 12, 2020, the Governor declared COVID-19 a public health emergency; Wisconsin schools were ordered closed the next day (Wisconsin Department of Health Services, 2020a, 2020b). Closures expanded further with the Governor's issuance of Wisconsin's Safer at Home order on March 24, 2020 (Wisconsin Department of Health Services, 2020c), which remained in place until a Wisconsin Supreme Court decision lifted it on May 13, 2020 (Supreme Court of Wisconsin, 2020b). The Safer at Home order mandated social distancing and directed all Wisconsin "businesses, including essential businesses and operations... to the greatest extent possible, use technology to avoid meeting in person, including virtual meetings, teleconference, and remote work (Wisconsin Department of Health Services, 2020c, p.3)." Residents were ordered to stay home at all times except when engaged in:

- "Essential activities," including obtaining health care or medication, food, outdoor activity with social distancing measures in place, and caretaking (Wisconsin Department of Health Services, 2020c, p.7).

- "Essential government functions," including first responders, emergency personnel, court personnel and jurors; corrections personnel; child welfare and housing personnel, and military members. The order specified that "Essential Governmental Functions means all services provided by the State, tribal, or local governments needed to ensure the continuing operation of the government body and provide and support the health, safety, and welfare of the public;"' it directed each government body to determine which functions it performed were essential and which staff were needed to perform essential functions (Wisconsin Department of Health Services, 2020c, p.8).

\footnotetext{
${ }^{1}$ The Federal Communications Commission defines broadband as service that provides at least $25 \mathrm{Mbps}$ (megabit per second) download and 3 Mbps upload speeds: https://www.fcc.gov/consumers/guides/broadbandspeed-guide
} 
- "Essential businesses and operations," which included, among other exceptions, grocery stores, pharmacies, food production companies, nonprofit charitable and religious social service organizations, gas stations, banks, hardware stores, "critical trades", home-based care, and essential transportation (Wisconsin Department of Health Services, 2020c, p.9). Restaurants and bars were ordered closed except for take-out or delivery; child care providers were ordered to prioritize families in which parents were designated as essential workers.

- "Minimum basic operations" to allow companies to protect inventory and physical space (Wisconsin Department of Health Services, 2020c, p.15).

- "Essential travel," such as to engage in any of the aforementioned activities, provide caretaking, or return home (Wisconsin Department of Health Services, 2020c, p.15).

- "Special situations" working in or receiving services related to health care, human services, and essential infrastructure. The order specified that "human services operations shall be construed broadly to avoid any impacts to the delivery of human services" (Wisconsin Department of Health Services, 2020c, p.4).

Courts followed a similar pattern; the Wisconsin Supreme Court suspended all in-person hearings for Wisconsin appellate and circuit courts on March 22, 2020, and on May 22, 2020, allowed proceedings to resume contingent on local safety plan approval (Supreme Court of Wisconsin, 2020a, 2020c). In the early months of the pandemic, most of Wisconsin's confirmed COVID-19 cases were limited to only four counties; however, by fall of 2020, COVID-19 infection rates grew significantly statewide; nearly every county in Wisconsin received a designation of "critically high" activity (i.e., more than 1,000 cases per 100,000 residents) by November 2020 (Knapp, 2021; Wisconsin Department of Health Services, 2021).

As the pandemic spread, many Wisconsinites experienced unemployment and economic hardship, including parents served by the child support program. A wellestablished relationship exists between compliance with child support obligations and NCP ability to pay ordered support (Bartfeld \& Meyer, 2003). NCPs with low earnings pay less in child support, and a lower proportion of the amount they owe, than their better-off peers (Bartfeld \& Meyer, 2003; Chen \& Meyer, 2017; Goldberg, 2015; Nepomnyaschy \& Garfinkel, 2010) and often experience difficulty meeting their own basic needs (Brito, 2012; Ha et al., 2018; Hodges \& Vogel, 2020; Vogel, 2020a, 2020b). Between February and April 2020, Wisconsin lost 407,800 jobs; unemployment rates rose rapidly from $3.3 \%$ in February 2020 to $14.8 \%$ in April 2020 (Wisconsin Department of Workforce Development, 2020).

The intersection of public health directives limiting in-person contact and economic downturn forced child support agencies to grapple with difficult decisions. Agencies had to decide how to keep services accessible at a time when many customers were experiencing financial hardships that could reasonably be expected to affect their child support situations, heightening the importance of being able to obtain information. For the most part, the Wisconsin and federal governments left decision-making about implementing remote work for staff up to counties. Wisconsin's Safer at Home order allowed counties latitude to determine whether human services agencies, broadly defined with an explicit goal of avoiding service 
interruptions, should remain open or close (Wisconsin Department of Health Services, 2020c). The federal Office of Child Support Enforcement (OCSE) left decision-making about remote work for child support agencies up to states and localities, noting that the Internal Revenue Service allows teleworking for staff with access to Federal Tax Information, provided that federal data security requirements are met at offsite work locations (Office of Child Support Enforcement, 2020b; see Internal Revenue Service, 2021). The federal government also provided guidance on allowable spending for child support programs during the pandemic, including temporary cell phones for staff, mobile hotspots, and personal protective equipment (Office of Regional Operations, 2020). OCSE also explicated state authority to decide whether to allow verbal or electronic signatures (Office of Child Support Enforcement, 2020b; Office of Child Support Enforcement, 2009), and defined processing child support payments as an essential function (Office of Child Support Enforcement, 2020b).

\section{The Current Study}

\section{Sample and Recruitment}

The sample for this study included child support agency leadership and frontline child support workers from five Wisconsin counties. Given that the prevalence and timing of COVID-19 infections varied across counties, and public health directives affected localities differently, the research team selected county child support agencies purposively to identify a broad array of experiences confronting the pandemic. As such, we considered three county-level characteristics when selecting county child support agencies for inclusion:

1) Geographic location. We selected one county agency from each of Wisconsin's five regions-Southeastern, Northeastern, Northern, Western, and Southern.

2) County size. We considered state-designated county size when selecting agencies. Sampled agencies were located within one large or extra-large county, two small counties, and two medium-sized counties.

3) Confirmed positivity rate. We compared each Wisconsin county's confirmed positivity rate (i.e., the number of confirmed positive cases per 100,000 people) ${ }^{2}$ We selected one agency in a county with lower-than-average rates, two agencies whose county rate was near average, and two in counties with high rates.

The research team used these criteria to generate a list of potentially eligible county agencies and initiated outreach to five county child support agencies meeting the criteria. Outreach began with the child support agency director. All directors invited to participate in the study agreed to participate. The research team asked

\footnotetext{
${ }^{2}$ As of October 28, 2020, relative to the Wisconsin state average of 3635 confirmed cases per 100,000 people.
} 
each director to identify one or more child support case managers or supervisors for the research team to invite to participate in a separate interview. Staff members were notified by the research team that participation in interviews was entirely voluntary. All staff members (11 invited sample members in total) agreed to participate and completed an interview.

Interviews occurred in January and February 2021. We used a semi-structured interview protocol to guide the interview process. Interviews consisted of a core set of questions applicable to all respondents, as well as batteries of questions specific to the child support director and staff roles. The protocols included questions on changes to the physical office environment, staff work arrangements, service delivery methods, and court processes that resulted from the COVID-19 pandemic and changes over time; factors affecting agency decision-making; actions taken, and resources procured, to help facilitate transitions to remote work; perceptions of the benefits and disadvantages associated with different service formats; challenges encountered and strategies to address them; and lessons learned and plans for the future. Interviews lasted approximately $90 \mathrm{~min}$. Each respondent provided consent to take part in the research and permission to audio-record their interview. All recruitment and data collection efforts were approved and overseen by the University of Wisconsin's Institutional Review Board.

\section{Analysis}

Interviews were professionally transcribed and then read into NVivo 12 software for coding. Data were analyzed using a hybrid inductive-deductive (Fereday \& MuirCochrane, 2006) thematic analysis approach (Braun \& Clark, 2006; Vaismoradi et al., 2013). We developed an initial codebook using a priori codes based on the research questions. We coded an initial round of transcripts using this scheme, and new codes were added (as separate codes or subcodes) when new themes emerged (Crabtree \& Miller, 1999; Fereday \& Muir-Cochrane, 2006). Early transcripts were double-coded, and the research team engaged in memoing and peer debriefing throughout the coding, analysis, and writing process (Franklin \& Ballan, 2001; Nowell et al., 2017; Schreier, 2012).

\section{Findings}

We present findings from interviews as follows, organized by the aforementioned research questions. First, we describe how child support agencies adapted physically due to the pandemic, including approaches to office closures. Next, we described how agencies modified where, when, and how staff worked. Then, we discuss how agencies adapted service delivery methods given limitations on in-person interactions. Throughout each of these sections, we highlight challenges, successes, and opportunities identified by directors and staff resulting from these adaptations. Next, we describe lessons directors and staff learned by working in new ways during the pandemic. Finally, we discuss director and staff expectations for whether and how 
changes to staffing and service delivery will persist in the future. We include quotes where appropriate, sometimes lightly edited for clarity or brevity.

\section{Adaptations to Child Support Agency Physical Spaces}

\section{Agency Closures}

A key decision that child support agencies had to make early in the pandemic, and had to revisit as the pandemic unfolded, was whether or not agencies should close to the public. Among the agencies whose staff we spoke with, closures played out differently across county contexts and across time. Two agencies never closed fully to the public; one of these two moved to appointment-only status for customers with a goal of completing as many processes as possible remotely, and the other accepted customers, but enacted new health and screening measures. Two agencies closed to the public initially, with staff interacting with customers remotely via virtual tools exclusively rather than face-to-face, until reopening to the public weeks or months later. The fifth agency closed to the public in March 2020 and had not reopened as of January 2021. Decisions about closures were made locally rather than directed by the state. Local COVID-positivity rates, consultation with local public health departments, and direction from county administration informed child support agency directors' decision-making about public access to agencies. When child support agencies shared building space with other departments, such as other human services agencies or courts, county administrators typically determined closure status for all offices within a county building, rather than leaving the decision up to local directors.

\section{Adaptations to Staff and Customer-Facing Spaces}

Directors made a broad array of adaptations to staff workspaces and spaces where customers access child support services, with an explicit goal of prioritizing safety and public health. Described one director:

We have to keep our people safe and we have to keep doing what we do. Because at the end of the day, the show must go on. We provide what I consider to be an essential service. Child support shuts down, we've got problems in society. So, it was a matter of making sure that the wheels kept rolling, but everybody had their seatbelts on, and the airbags were ready, and we were getting to the end goal that we needed to get to, but we needed to do it as safely as we could. And that's still, to this very day, what we're doing.

In staff work areas, these included changes to seating arrangements to allow for six feet of distance in agencies where frontline staff did not have private offices with doors, and the addition of visual cues to indicate six feet of distance between workspaces. Directors described instructing staff not to congregate in common areas, sanitizing workspaces "constantly," and keeping papers and objects on staff work surfaces to a minimum. 
Agencies also made changes to customer-facing spaces. In entryways, agencies enacted processes such as creating no-touch pathways to offices; instituting health checks or temperature checks; and providing masks, hand sanitizer, and gloves for customers. Within agency reception areas, child support agencies made modifications to limit airborne transmission, such as adding or modifying plexiglass walls to separate customers and reception staff and limiting the number of customers who could wait in reception areas. To limit surface transmission, they removed high-touch surfaces such as phones, computers, flyers, and toys and games for children, and reduced the number of chairs in lobbies to facilitate distancing. Agencies typically posted signage about rules for masks, distancing, and capacity maximums in waiting areas, and some also provided visual cues such as tape on the floor spaced in six foot intervals to remind customers of distancing requirements. Within interview rooms, agencies made adaptations such as obtaining and placing portable plexiglass shields between customers and staff; swapping out furniture to facilitate distancing; and adding phones to allow for phone meetings with staff in lieu of face-to-face meetings. Staff and directors described sanitizing these common areas very frequently.

In addition to physical space changes, agencies enacted new processes and requirements to further promote safety for customers and staff. These included, across agencies, mask requests of customers and mask requirements for staff; adding sanitizing stations and reminders about frequent handwashing; and enhanced cleaning protocols, particularly for high-traffic areas such as lobbies and restrooms. Most counties reported requiring staff with any COVID-like symptoms to work remotely, regardless of their regular schedule.

Directors and staff noted several benefits and practice innovations that emerged from changes to physical spaces. For example, adding a plexiglass wall to the lobby helped one agency to address pre-pandemic confidentiality concerns about customers' abilities to access paperwork on the reception desk. Obtaining portable plexiglass dividers turned out to be doubly helpful for another agency; in addition to using them for meetings with customers, the dividers provided a much-needed way for supervisors to perform side-by-side training of new staff. Most agencies added new mechanisms for customers to turn in required materials and make payments. One agency, which closed completely to the public, added a fax machine to the building's entry so customers could transmit materials to staff; leadership of the departments housed in this building also worked together to implement a practice change in which the building's receptionist began acting conduit for customers to drop off materials for staff, and allowing staff to leave documents for customers to pick up without accessing the child support office directly. Two agencies installed drop boxes to allow customers to drop off paperwork and make payments; two others with drop boxes already in place started accepting a broader array of materials through their drop boxes. Staff highlighted the flexibility afforded by drop boxes particularly for customers who make payments outside of automatic income withholding, a benefit they expected would persist after the pandemic's end. 


\section{Adaptations to Staff Work Arrangements}

In most agencies, staff work arrangements changed dramatically on account of the pandemic, with staff working in new, and generally more flexible, ways. In this section, we describe changes agencies made to: (1) where staff worked, (2) when staff worked, (3) the technology staff used to do their work, and (4) the communication and supervision adaptations agencies made. Throughout, we describe the challenges, successes, and opportunities described by directors and staff as they adapted to new ways of working.

\section{Changes to Staff Work Locations}

Even in agencies that closed to the public, directors also had to decide whether to allow staff access to agency offices. The idea of staff working remotely was, across agencies included in this study, entirely new; exclusively or with rare exception prior to the pandemic, staff worked within an agency. Described a supervisor:

We were 100 percent in the office all the time before this. So this was, I mean, not even just reinventing the wheel, but realizing there was a wheel to invent. It's just not something that we'd ever had to really consider. So much of this work is meant to be person to person. You're dealing with a lot of incoming paperwork all the time, so from the standpoint of trying to be lean, trying to be efficient, you really want to get the work as it's coming in to try to stay on top of it because, certainly for some of the work that we do, there are important deadlines that need to be met.

The extent to which agency directors had discretion over whether staff worked at home or in an agency varied locally and across time; initially, in most agencies, all or all but a few staff members, such as receptionists, call center staff, or others whose jobs could not be performed remotely, were assigned to work from home at the direction of county administrators. After this initial period where all or most staff worked offsite (which lasted days or months depending on the agency), one agency was required by county administration to cease remote work and return to the office full time, while all other directors reported being granted more autonomy by county administration to make decisions about staff presence within the agency. One director described:

There's no, like, set policy from the county [now]. I mean, it's not like we've gotten a whole lot of direction, and that's not a criticism. It's just that, you know, we've been making it up as we go along and nobody really knows what's safe.

Agency directors and their staff quickly identified that certain functions, including those performed by administrative staff and paperwork-intensive processes, often required some level of office presence. For this reason, four of the 
five counties ultimately landed on a hybrid work rotational model, in which directors assigned staff to work in the office some days and at home other days. Directors made decisions about the number of days staff would spend in the office based on the functions they performed and the feasibility of performing duties off-site; staff preferences, when health conditions allowed for greater flexibility; and taking into account county public health guidance about COVID-19 infection rates.

Staff and directors noted several downsides to remote work for staff, particularly when remote work was the only option available, or when staff were not allowed to access the office as frequently as they liked. Prominent in these downsides was frustration stemming from the inability to perform certain functions while working remotely. When technology failed to work well, or to work as intended, it created substantial frustration for staff and impeded their work. This was a concern particularly highlighted in more rural counties that lacked adequate broadband access and was also mentioned as a concern early on when struggles to obtain soft phones and laptops were greatest. Additionally, several staff and directors highlighted the costs passed to employees because of remote work, from office supplies to home electric bills to upgraded internet service plans. Further, directors and supervisors emphasized downsides related to collaboration, the effects on agency culture and camaraderie, and concerns about isolation. These issues were of particular concern for new hires; directors noted that on-site training typically occurs side-by-side and they lamented the difficulties associated with helping new staff learn tasks and understand an agency's culture and practices while working alone at home. Noted one director:

I miss, like, just being able to pop in somebody's office and, "Hey, what about this?" I mean, you can still do it, you could pick up the phone, but it's just not the same. And some people who are new or some people are struggling, I think really feel isolated.

Additionally, directors and some staff noted that while some people's homes are calmer and quieter than the office, others have distractions at home that can make remote work difficult. Finally, agency staff also highlighted the challenge of many processes taking longer, due to only being in the office to receive materials 1 or 2 days per week, or simply due to the number of new steps involved in completing work. Not having access to mail and printed materials at home remained a persistent issue for staff, as lack of access created delays and required additional tracking of documents sent to the printer from outside of the office.

Despite these challenges, agency directors and staff generally reported that many aspects of remote work for staff were highly successful, particularly given the limited time and resources available to prepare for the transition. Across agencies, directors and staff described as a key benefit that having remote work options allowed child support agencies to function during the pandemic, while also mitigating risks to employee and customer health. This meant not only continuing to provide services, but also to avoid furloughing staff. Directors often described being unsure, prior to the pandemic, if a service model that involved staff working offsite was possible; they acknowledged and celebrated the fact that despite a long history of providing 
in-office services, very little time to prepare for the transition, and many challenges encountered, they were able to make remote work happen. Staff and directors also emphasized the benefit of convenience for staff; virtual work options allowed staff to deal situations at home without needing to take time off work, as well as to eliminate commute times and parking costs. Several directors noted that these flexibilities functioned as "perks" for staff, and staff, for their part, generally concurred with that assessment. Noted one director:

I think people like that flexibility. Retaining people, trying to retain staff longterm, has been one of our struggles overall, because of what it takes to train people and just to get good people in the office. We try to make it attractive for people, and this has helped.

Staff emphasized that having the opportunity to work remotely at times meant that they were able to catch up on certain tasks that required concentration; directors, for their part, noted that some staff have an easier time focusing at home than in the office. Stated one staff member:

I think the morale is better for some people. For me especially, I seem to get more work done when I'm at home than when I'm in the office. I think people's spirits are a little bit lifted when they're able to work at home, or have the ability to. They're not as stressed out. You don't see the office politics that go on every day when you're working remotely.

Agency staff described several factors that helped facilitate this transition to remote work, several of which were related to staff and relationships. First, they emphasized the role all agency staff played in facilitating the transition to remote work. Staff credited their agency's directors for being willing to try something new and providing support throughout the process; directors, for their part, cited staff flexibility, adaptiveness, and willingness to communicate throughout the transition. Described one director, "What's contributed to it the most is just the-flexibility of our staff to embrace it and to try it. And like give feedback of what's working for them and what's not, and just working together to overcome it." Across agencies, directors also emphasized that strong communication with staff about their needs and providing information about virtual work expectations helped facilitate the transition to working remotely. Nearly universally, agency directors and staff also praised the efforts of their county IT staff to help obtain the tools staff needed to work offsite, despite many competing priorities. Agencies also shared that embracing new processes, such as e-filing of court documents, as well as agency director efforts to obtain the necessary technology, made remote work for staff possible.

\section{Changes to Staff Schedules}

Creating work schedules for staff during the pandemic was a far more complex task than in the pre-pandemic world. Prior to the pandemic, staff typically worked a set schedule; some staff worked agency- or county-specific hours that applied across staff; others were allowed to choose their hours within several time range options 
available to agency staff. Directors considered a number of factors while setting staff schedules. Health considerations factored prominently in decision-making. Two agencies rotated staff in groups on the same days to confine spread should a case be identified in the office. Most agencies adjusted the number of staff in the office as COVID rates peaked and waned. All agencies took into consideration where staff sat physically in relation to each other. In two agencies, all staff had private offices, making it easier for staff to work in the office while distancing.

When setting schedules, directors also sought to ensure that all staff had enough time in the office to handle essential in-office functions, such as paper-based tasks and filings, mail correspondence, printing, shredding, and managing paper files. Agencies with hybrid options generally sought to ensure that other staff members had at least 1 day in the office; in most agencies, supervisory staff had more days in the office than other frontline workers, to allow them to answer questions, provide support, and train new staff; and reception and administrative staff were typically assigned more in-office days than other staff due to allow them to interact with customers. Generally, the number of days staff spent in the office relative to at home increased with time.

Though schedules were generally set on a regular basis, directors had to make decisions about whether and how to allow staff flexibility, either on a regular basis or as-needed. Across agencies, directors described being mindful of the challenges staff faced balancing work and other activities, particularly related to caregiving; they knew many staff had children at home participating in school virtually or whose childcare provided had closed. This often meant juggling children's needs with work responsibilities in new and challenging ways, especially, as directors noted, for single parents or parents whose partners lacked job flexibility. Other staff had caretaking duties for older adults that increased during the pandemic. To help address this challenge, directors of two agencies allowed staff to work nonstandard hours on a regular basis (a practice not typically allowed prior to the pandemic); two others allowed kept work hours the same but allowed more flexibility as-needed. Described a director:

A lot of our workers have young or school aged children, and now the [district] has been remote the entire school year. So you know, their kids are home and they're probably not old enough to be by themselves, and they have to make sure that they're on the remote school. People have some days they just can't come in and, you know, daycares aren't accepting new kids. We've had to work around that... Sometimes people are, you know, getting things done during the day. And so then, they might be putting an hour or two later on, you know, seven o'clock at night or working early, 6:30 in the morning or whatever. We've had to accommodate that a little bit.

Another director emphasized that flexibility in scheduling was important not only for allowing staff to get their work done given other commitments, but for staff morale:

We do flex schedules here. It works. I just want them to hit their 80 hours. That's a-what's the word I'm looking for? Like a morale issue too. It's not a 
cookie cutter scenario anymore. You got to adapt to everything that they have going on, like some kids are in school, but they're little so they need help getting on virtual. So, they need to take off a little bit of time to make sure the kids get to where they need to be and all that stuff.

Several directors, as well as staff members, noted that the state expanded the hours during which the state electronic child support system was available to staff, and that this added accessibility helped support flexibility in scheduling. Directors described that schedule flexibility had the potential to make monitoring more difficult, but also meant staff were able to complete their expected work rather than asking for time off. Directors and staff noted that this flexibility had the added unanticipated benefit of giving customers access to staff at a broader array of times.

Directors described that arriving at a schedule that balanced staff needs, customer coverage, and public health considerations was a challenge, but one that generally resulted in successfully meeting these goals. Staff, for their part, recognized that directors in their agencies sought to balance health considerations with the needs of staff to access the office periodically, and nearly universally described that directors were doing their best to support staff needs despite considerable uncertainty and constraints. Described one frontline worker:

I think [early on] sometimes they were a little more, I don't want to say strict, but they were a little more stringent about days where they only wanted us to go in one day a week, to really reduce the number of people, really reduce the traffic in the office. But for the most part now, I would say they're flexible because some staff have expressed that it's a little stressful to try to accomplish all those things only on one day, which I can understand too. So now I think we have a little more leeway where some folks are going in like two or maybe three days a week.

\section{Changes to How Staff Worked: New Tools}

A major challenge staff from all agencies encountered when they started working offsite all or some of the time was obtaining the tools necessary to do their work. Given that child support agency staff typically worked in an office setting prior to the pandemic, in order to facilitate staff working remotely all or some of the time, child support agencies had to provide staff with new equipment and tools that allowed them to work offsite. One of the first tools agencies needed to provide for staff to facilitate remote work was computers. Most staff did not have the technological tools required, such as laptops or secure connections to the agency network, to work from home. Summarized one director: "Working from home was entirely new to them. [Our agency] did have four laptops prior, but those were for people who went to court."

Agency experiences obtaining laptops varied substantially. One agency, which worked remotely only for a short while, was able to borrow laptops from the county information technology (IT) department in the short-term, whereas the other agencies had to buy what they needed. Two of these four agencies were told procurement would take months. One purchased laptops from a department store to fill this gap. 
In the other, staff were allowed to use home computers or old county computers until tablets arrived, but even with these steps, the agency did not have enough computers for all staff for a period of months, leading to prolonged unproductive time. The other two agencies were able to procure laptops through county IT departments relatively quickly and use desktops in the interim. Two agencies had to absorb all or part of the cost of these new computers; the other two were able to access grant money to cover most of the costs. Most agencies also obtained a host of hardware tools to support work processes, such as docking stations, mice, keyboards, monitors, and headsets.

In addition to obtaining new computers, directors needed to work with local IT departments to ensure that new and existing computers for staff had the software necessary to perform their work. All agencies needed to obtain VPN software for computers through their county IT departments and described VPN tools as essential to accessing the child support databases and systems needed to perform their work. Agencies also obtained new communication tools, typically through their local IT departments, such as Microsoft Teams, Skype, Zoom, and WebEx. Most agencies described not having or not often using such software for their work previously.

Several agencies also invested in new within-agency technology. These included computer screens for interview rooms to allow customers to visit with staff from the agency even if staff were working offsite, and scanners to transmit mail to staff working remotely. Staff highlighted the benefits to efficiency and time management afforded by having mail scanned and emailed, particularly given limited office access, with one stating:

That is a game changer because when you have someone working at home, if they are wondering what's in their mail slot and they have a coworker who's in the office, they can essentially pull the hard copy mail out of their bin, scan it, and it will go straight to that person's email. So even though they don't have the paper copy, you know, they can see what's there waiting for them. So then at home, you know, they have an idea of, "Okay, what can I do while I'm remote?" You know, "What doesn't need my signature; what doesn't need this or that?" It also helps them plan for the next time they are in the office, because then they know what's waiting for them.

A problem that plagued all agencies for various durations during the pandemic was telephone technology. In no agencies did staff have work-provided cell phones before or during the pandemic; while staff in most agencies described using their cell phones to text or call coworkers prior to the pandemic, staff were reluctant to use their personal phones to reach customers. Described one supervisor, "Particularly in this job, you know, you're making phone calls out to people who don't always want to hear from you. So, you know, not wanting your personal number recorded on somebody's phone, who is in your caseload, is understandable." In two agencies, staff used their own cell phones and used the *67 feature to mask the number. Broadly, staff noted that using $* 67$ presented its own challenges, as many customers will not answer a phone number from an unknown caller. In recognition of the costs deflected from agencies to staff by using personal cell phones, the director of one of these two agencies tried to obtain reimbursement from the county for staff personal 
cell phone costs, but county administration denied the request. In the other three agencies, directors ultimately obtained soft phone technology for staff, allowing them to make phone calls through their computers. However, obtaining soft phones took several months, creating frustration on the part of staff and customers, process delays, and impeding or preventing staff and customers to communicate through modes other than mail or email. These challenges were particularly pronounced early in the pandemic, when office access was highly limited. Staff described obtaining soft phones as "a complete game-changer" for their ability to connect with customers and provide a broad array of services.

In addition to issues obtaining the necessary equipment, agencies encountered a number of challenges transitioning staff to using new technology tools. Directors and staff in four agencies highlighted broadband access issues; directors and staff who lived in rural areas had poor or unstable internet connections or could not obtain any internet. In an agency located in a small county, every agency staff member needed to upgrade their home internet in order to do their jobs, and the county would not help with the associated costs. Described this agency's director:

There were days when I was kicked off seven times or eight times in a day. I felt like I was spending more time logging into my computer than work, you know, being able to get work done. Every one of us had had to make changes to our internet program or palette. You know, we had to upgrade, we all had to upgrade. I mean, we all had high-speed internet, but we all had to upgrade the limit or what our speed was, so that we could continue to function and work at home.

In another small county agency, some agency staff had no internet access at all at and needed to purchase service; others had very slow satellite connections that greatly impeded functionality. Described the director, "I live out in the country. And I have satellite internet. So that was a big issue because it made it everything-it was so slow, like I almost couldn't even work sometimes." In two agencies, directors described that even in parts of the county where staff lived who had adequate internet generally, the load of having so many users at home at once caused periodic disruptions for staff. Additionally, directors of several agencies noted that some staff were not comfortable using new technology at first, and attempting to help staff learn new technology remotely was not an easy task-particularly as they were often only just learning how to use this new technology as well.

\section{Changes to How Staff Worked: Communication Strategies and Supervision}

In addition to changing the technology used to do their work, agency leaders and frontline staff needed to change the ways that they communicated with each other. Across agencies, directors and staff emphasized that finding ways to communicate successfully was of great importance, due to the collaborative and interconnected nature of their work. Before and during the pandemic, staff described frequently drawing on each other's experience and relying on each other as sounding boards for difficult situations, particularly in agencies that specialized by function. As one director described, "Our people are so reliant on one another. 
You know, we're so specialized. To just get to court, you essentially go through almost every one of the support services units, and you hit the attorney on top of it." When staff started working at home most of the time, their interdependence heightened, particularly as the staff working offsite on a given day relied on the staff working within the office to coordinate print jobs and mail processing. Prior to the pandemic, agency staff described that many aspects of communication among staff occurred in-person. Working together in an office routinely and on the same schedule made walking down the hall to get an answer to a question or help from a coworker a relatively frequent occurrence. When staff were not all together in an office, communication had to take on new forms to allow work to continue.

Agencies adopted several synchronous and asynchronous communication practices for staff. To distribute information broadly across the child support agency, directors made more frequent use of group email messages in lieu of announcements that would have been made in agency-wide meetings prior to the pandemic. Directors and supervisors emphasized the importance of communicating frequently about office operations, policy changes, and other issues that affect staff, particularly in such a period of great uncertainty. When staff first started working remotely, directors provided guidance about telework expectations and use of technology, either through formal documents (such as telework agreements or documents describing expectations for in-office tasks versus at-home tasks) or less formally through email and conversation. Additionally, in most agencies, directors convened large group staff meetings via Microsoft Teams. Group meetings allowed leaders to give all staff information simultaneously; gauge staff reactions via video; and provide a sense of normalcy for staff by replicating their usual in-person processes. Agency staff noted some challenges with this format, including bandwidth difficulties and slowdowns in rural counties, discomfort among some staff about being on video, and challenges occurring within staff home environments that made it difficult to fully engage.

In addition to using technology to address agency-wide issues, directors and staff used technology-based interaction tools for one-on-one and small group communication. Staff reported that they typically emailed each other one-on-one for issues that did not require an immediate response and texted each other for time-sensitive issues and questions; across agencies, staff noted that their use of email and texting with each other increased relative to pre-pandemic times. To facilitate instantaneous and synchronous communication, four agencies started using Microsoft Teams for video chats with each other, as well as for group textbased chat spaces. Staff found these chat features very helpful for obtaining group input and quick responses. Described one supervisor:

I have a separate chat that's all of my group. So, if they do need something, they just send a message out like, "Is anybody there that can do...," you know. And then someone will pipe in and say, "Yeah, I'm here, I got it." And, it's really great tool to be able to jump in and say, "Hey, is anybody having issues with this or that?" And all of a sudden, you know, I'm getting all these responses. "Nope, I'm good. Everything is good, everything is good. It's a little slow, you know." So I'm really thankful for that resource. 
Though not without challenges, staff and directors broadly considered communication and collaboration among their teams as considerable successes. Described one supervisor, "I'm really proud of everything that the team has done in terms of stepping up for each other and really, you know, realizing that it takes the whole team to keep the train moving." Another concurred, stating:

Staff have been wonderful with checking on things for each other. You know, if they have something that they know like, "Oh, I'm waiting on a stipulation for this, or I need to have this filed and I'm not in the office to sign this affidavit" or whatever. Workers have been really wonderful about checking each other's mail bins if they have something urgent going on or stepping in for an appointment if they need to do that really quickly. I have to say, this could have been a lot more of a headache than what it was.

From the perspective of directors and staff, a key to facilitating successful communication within agencies during the pandemic was strong relationships and communication prior to the pandemic. Across agencies, staff typically texted with each other regularly prior to the pandemic and described generally feeling comfortable reaching out to each other in that way already. Leadership and staff from most agencies also described a strong sense of trust among and across staff and supervisors prior to the pandemic, which helped to facilitate strong communication when they could not be physically together. Stated one director:

Things really work differently and better when you have trust and there's that mutual respect. And a level of understanding that the management team isn't going to do anything that's not in the best interest of the people, whether that's the team or whether that's the people we serve.

Having staff offsite some or all of the time also required leadership to supervise staff in new ways. From the perspective of supervisors and directors, monitoring staff performance and staff well-being was a more straightforward task pre-pandemic, as working within the same office provided them opportunities to overhear staff interact with customers, have conversations with staff as issues arose, and reduced barriers to staff seeking advice or support. To provide supervision and support, directors and supervisors reported regular one-on-one communication between staff and supervisors, often weekly, via Teams, FaceTime, or telephone. They described the purpose of the check-ins as to hear how staff were doing, talk about questions that arose during their work, and identify and discuss needs and issues. To monitor staff performance, directors and supervisors needed to engage in new technology-based strategies such as monitoring clock-in/clock-out times used by payroll software; spot-checking cases; monitoring worklists; generating reports; and checking Microsoft Teams status indicators. Directors cited monitoring staff performance while staff worked remotely as a challenge. Noted one director: "From a management standpoint, straight up, is difficult to make sure that everybody's doing what they're supposed to be doing. Luckily... I'm able to go in look at certain reports. Look to see who's working on what, how many cases have they touched each day." 
One supervisor also noted the limitations of reports, while helpful for some purposes, much caseworker effort goes uncaptured:

There is a state report that tracks system activity, which captures certain events and activities performed in state systems, but doesn't account for more abstract work, like time spent doing case assessment, court prep, historical research on a case, etc. There are a lot of things that happen in case work that can't be measured like that, so some days it may look like not much was being accomplished when reviewing a system activity report, when in fact the employee may have been in virtual court hearings all afternoon, or working in a spreadsheet to monitor case timelines, etc.

Despite these limitations, directors and supervisors generally felt that staff productivity was high, and most staff were doing their best under difficult conditions. Directors from several agencies noted low levels of customer complaints-typically an early sign that a caseworker has not been responsive.

Remote work, and the context of the pandemic itself, also made supervisors mindful of the need provide support to staff in new domains. Staff mentioned that leadership made concerted efforts to keep staff engaged, such as through encouraging emails and group meetings. Leadership and staff in one county in particular highlighted efforts related to mental well-being for staff, which included sharing articles and resources on mental health, having one-on-one check-ins with an emphasis on well-being and self-care, and surveying staff on needs and experiences. While providing this supervision and support was not without challenges, according to some directors and staff, these efforts also brought teams closer together. One director described:

I think [a success] is probably just finding ways to think outside of the box and communicate effectively [with staff]. Get them the information they need. Try to incentivize them to make payments and do what they're supposed to be doing. Keeping the staff happy and engaged and content as much as they can be with all the anxiety and unknown. It's been tricky. But by doing one-on-one check ins, and surveys, and emails, and keeping my door open all the time, and talking about it at staff meetings, like, "It's all right if you have a bad day." If anybody needs to chat, we're always here.

Directors emphasized that a key facilitator of successful supervision for remote employees was building team cohesion, and relationships between staff and supervisors, prior to a crisis. Stated one director, "You've got to be taking care of [staff] all along... you've got to make sure that people have enough buyin and are happy enough. So that when you do need them to step up, you know, during a crisis, they will." Staff, for their part, frequently noted the accessibility and responsiveness of directors in providing supervision and support during the pandemic. 


\section{Modifications to Service Delivery}

Child support agencies are public-facing entities whose customers are obligated by court order to comply with their services. Therefore, while providing staff with the tools that they needed to work offsite successfully was a crucial first step in the transition to virtual offerings, child support agencies also had to identify and implement strategies to connect with and make services available to customers when faceto-face offerings were limited or impossible. In this section, we describe (1) how agencies adapted methods of providing services to customers during the pandemic; (2) how courts adapted court-based services and processes; (3) how these changes affected service continuity and engagement strategies; and (4) implications of these service delivery changes on the ability of customers to access services.

\section{Adaptations to Agency Methods of Interacting with Customers}

Prior to the COVID-19 pandemic, the child support agencies included in this analysis typically interacted with customers face-to-face, either through drop-ins or appointments made at the child support office or at court around the time of a hearing; by mail or process service; or by telephone, including outbound calls initiated by staff or inbound calls, often fielded by a call center in-house or centrally. The pandemic greatly interrupted these traditional means of interaction. For agencies that closed, face-to-face interactions became impossible; for those that remained open, additional layers of effort, such as requiring appointments, were common; and staff found that some customers hesitated to visit the office in-person due to health concerns. The suspension of in-person court proceedings rendered that opportunity for face-to-face contact temporarily inaccessible. Mail processes still occurred, though were more difficult due to limited in-office time for workers. And, the aforementioned telephone struggles made it difficult for customers and staff to connect, particularly in the early months of the pandemic.

And yet, agencies were aware that customers needed to reach them, perhaps now more than ever, as they experienced income loss, had stimulus checks intercepted, and encountered questions related to their unemployment benefits. As a result, agencies needed to innovate around approaches to communicating with customers, by leveraging previously available methods and creating new ones. For customers who needed to access the agency in person, agencies implemented or made broader use of drop boxes for payments and documents; provided expanded contact tools, such as fax, phone, and video options in lobbies and conference rooms; and in some agencies at varying times during the pandemic, allowed customers to visit the reception desk or have face-to-face meetings with workers with health precautions in place.

Even in agencies that remained open to the public, directors and staff emphasized that they sought to provide alternate means to accomplish tasks; most commonly, these efforts included phone, email, and website options. Staff reported increased phone contact with customers, particularly once soft phones were available in agencies that initially did not have them, and handling processes that were once completed in-person, such as establishment interviews, via telephone. Staff from all agencies reported using email with customers considerably more than period before 
the pandemic and employing security features such as encryption to send emails. Agencies used email somewhat differently. In three, staff used a shared office email to communicate with customers; in two, staff communicated with customers directly from a worker-specific email address. Some staff used email primarily as an outreach tool to encourage customers to call them, due to agency concerns about confidentiality tools and customer difficulties with the encryption software. While directors and staff emphasized the helpfulness of email as an option, particularly during periods without phone access, they often emphasized that phone contact was preferable to email for sensitive matters or exchanging confidential information. Described one supervisor:

There was a period of time, right as the pandemic hit and we all went off site where [email] was really the only way people could get ahold of us quickly. I mean, because we didn't immediately have access to phones for everybody, customers couldn't come into the office, the building was closed. We were getting this influx of emails then, which, you know, we were happy to be able to communicate with people at all. And certainly, we had to kind of step outside of our comfort level with that, because we couldn't just say, "Well, we're not going to email response to anybody." I mean, this was really our only way to communicate. So we did have to kind of expand what we would normally allow in terms of email communication. "Try to keep it general; if you can't, you're going to have to encrypt," you know. So there was definitely much more emailing going on... As soon as they got access to their phones, we did pull back on that and say, "Just remember, the best way to reply is not through email," unless, you know, the person is indicating that's the only or best way to reach them. Really picking up the phone is the best option.

Agencies also leveraged websites as a key communication tool during the pandemic. Three agencies reported having robust websites in place prior to the pandemic, containing paperwork and other information for customers; another, by coincidence, launched their agency's site during the pandemic. Directors worked with county IT departments to expand on website capabilities to include fillable forms for customers that could be downloaded, emailed in, or dropped off, such as financial, job search, and medical capacity forms; modified websites to include information about COVID-19 related procedures; provided information on how to make payments, including online and drop box options when applicable; and allowed customers to send questions to a generic agency email account.

Staff reported using other options, like texting, video chat, and fax, with customers less frequently or not at all. Four agencies did not have a county- or state-supported texting program available to staff, and one had a one-way system that allowed for announcements but not two-way interaction; cost constraints and concerns or uncertainty about confidentiality and documentation requirements impeded agency use of texting. Staff generally did not meet with customers by video due to bandwidth constraints for customers, lack of familiarity with the software, privacy concerns, and lack of customer demand for video meetings.

Directors also recognized that, as options for interacting with the child support agency changed, they needed to communicate these changes and current agency 
status information to customers. In addition to website postings, agencies provided information on voicemail systems and by telephone; shared information using traditional media sources such as the local newspaper or on radio stations; issued press releases; and used social media such as Facebook posts. Agencies also used physical tools to share information about the agency's status, such as fliers and postings on buildings and by including information in mailings to customers.

\section{Adaptations to Court Hearings}

Courts, like child support agencies, had to change operating procedures during the pandemic with little time to prepare. Across agencies, in-person child support court hearings within their counties ceased in March 2020, then transitioned to offering virtual court hearings over a varying number of months. Courts in all five counties had pivoted to holding child support court hearings in virtual formats by the time of data collection, leading with paternity, order establishment and modification hearings. Most hearings occurred by Zoom with an option to dial in by telephone. Staff reported that, while some customers needed support to access Zoom, the process worked well for most customers and for court staff, and show rates have maintained or improved. Described one staff member:

The court sends them notice through the mail of the instructions for how to appear by Zoom. Like there's a link in there for them to type in their computer so that they can connect remotely like through video, or the opportunity for a phone dial in. ... The courts have liked it because we used to have people bring their children to the hearings, and the paternity and support establishment hearings are recorded. So, if the child is crying, it's difficult for them to take testimony and all that. The Zoom for that has really helped.

Enforcement hearings took longer to resume in part because law enforcement agencies sought to keep levels of COVID-19 in jails low and minimize law enforcement officer exposure to the virus. This meant that sheriffs ceased service of process and arrests of customers on child support-related warrants, to keep numbers of prisoners in jail at a minimum; courts, in turn, typically stopped issuing warrants or commitments. These limitations remained mostly in place at the time of data collection, though one county had recently resumed normal warrant and commitment procedures, and one had returned to using them on a limited basis.

These process changes had a number of implications for child support agency operations. During the period in which no hearings occurred, directors and staff had to work with courts to communicate changes, such as postponed hearings, to customers-sometimes multiple times. This required close coordination with court partners and significant time on outreach efforts to customers. As a positive consequence to these changes to legal processes, directors and staff from several child support agencies reported working with their court partners closely to collaboratively consider how to make the best use of court time given current conditions. This led to several innovations in the realm of court proceedings. First, in one county, the agency and courts developed an innovative new approach to enforcement court proceedings in lieu of contempt court hearings, targeted strategically at early 
intervention cases. In these proceedings, noncompliant parents are served, appear before a commissioner via Zoom, discuss factors contributing to noncompliance with the commissioner, and are given purge conditions related to communicating with the agency, employment-related efforts, and making payments. The agency had been actively seeking alternatives to traditional contempt prior to the pandemic, and the pandemic provided the necessary catalyst to drive this innovation forward. In another county, moving to virtual court processes drove the agency and courts to collaboratively innovate on new virtual pre-court meetings between child support workers and customers, to ensure that customers understand how hearings work virtually, discuss paperwork in advance, provide an opportunity for stipulated agreements, and answer questions. This county expressed excitement to have identified a method to streamline hearings and improve customer understanding of and engagement in court processes.

\section{Implications of the Pandemic on Child Support Service Continuity and Customer Engagement}

By identifying alternate means of engaging customers and facilitating in-person options for customers who needed them, directors and staff reported that they were generally able to maintain service continuity across domains, albeit with some gaps and slowdowns. Directors and staff both strongly emphasized their need to ensure that customers could continue to make payments. To do so, staff described that they initiated communication with customers in response to job changes, quickly attached income withholding orders when NCPs obtained new employment, and provided customers with methods to report job losses or changes virtually, such as through websites. Staff and agency resources also directed customers who pay directly instead of via income withholding to online payment options and continued taking payments physically.

A service area that experienced significant challenges was paternity establishment, which suffered interruptions due to court delays, delays as agencies implemented safety procedures and alternate plans to conduct genetic testing, and notary requirements. Described one frontline worker:

We used to do appointments for people to sign the voluntary paternity acknowledgement, where they agreed that the dad was the dad and, you know, we would fill it out for them and have them sign it and then we would notarize it. Well, with COVID, they couldn't even take a form to a bank or library to have it notarized. So we couldn't do the voluntary paternity acknowledgments with them, so every paternity case that we had was having to go on the court calendar. It kind of like clogged up our court times a little bit.

Ultimately, by the time of data collection, resumed genetic testing and paternity proceedings had resumed in all counties, by appointment in most counties, and several agencies had identified ways to streamline the process. For example, one made paternity interview forms available for download via website and allowed the forms to be returned by email. Agencies also enacted changes to genetic testing processes to improve safety. These included having lab vendors 
conduct testing instead of staff; switching to a self-swab model for customers, overseen by a child support staff member wearing personal protective equipment (PPE); reducing the number of staff involved in testing; moving testing to larger rooms; and limiting availability to specific days or by appointment only.

Enforcement processes also experienced some changes; though staff continued communicate with customers about enforcement by phone and email, when contempt proceedings paused, staff spent less time on contempt processes. Directors and staff also reported taking enforcement actions cautiously during the pandemic, given the significant economic hardship many customers were experiencing and difficulties communicating with customers directly. Agencies engaged in innovations to address enforcement issues effectively during the pandemic; for example, an agency started allowing customers to deal with vehicle liens by mail than in-person, and some made enforcement-related documents, such as job search forms, available online for download.

Directors and staff described several changes to service delivery broadly considered to be positive resulting from the COVID-19 pandemic. Most prominently, they found that the pandemic led to more proactive outreach from caseworkers to customers - a change they hoped would persist after the pandemic's end. Caseworkers needed to engage with parents in new ways because a means through which they typically interacted with customers about questions and issues-inperson court proceedings-were no longer occurring. Workers had more time to engage in proactive outreach due to reduced enforcement levels and contempt filings. Described a director:

Because we don't have our 100 percent of our enforcement ability, they're not prepping as many cases for [court]. So, what are they doing instead?... More communication with NCPs, CPs, more emails, more phone contact. Reach out to people early; take five minutes explain their court order where they've never had that before, because our people have 700 or 800 cases per caseload.

Directors perceived this outreach as a significant bonus for customer-caseworker relationships. One described:

And then the establishment workers, you know, they've had to call people more, and email people more to say, "Hey, Joe Smith, I see that we don't have an income holding you in place anymore. What's shaking?" So normally, we would have found that out in court, but since we weren't doing court for a long time, it forces them communicate, which I love. I've preached that since I've been here. You've got to reach out to these people. Because if you talk their language, they're going to be more willing to respond and communicate. So, that's been good.

Another positive practice change brought about by the pandemic described by staff was the opportunity to reimagine how to make processes less burdensome, or to work through processes in new ways. This led directors to examine opportunities to serve documents in new ways, to consider alternatives to signature 
requirements, and to assess which processes could be accomplished by mail or phone instead of in person. Additionally, in several counties, staff described engaging in efforts to provide parents with information about alternate methods for completing processes given court delays. One supervisor cited modification requests as an example-a process that takes months in normal circumstances and substantially longer in the context of the pandemic. She described:

We had a number of people calling me wanting to have their order modified right away. In situations like a pandemic, where somebody's circumstances are changed overnight, you know, you have people being laid off... The process is not built for that at the agency level. We don't have the authority to just stop the order. We don't have the authority to change the balances on the account. Even if you both agree, we can't just do that; there needs to be court intervention. So, situations like that where we can tell them, "Look, if you're really concerned about getting this stopped as quickly as possible, this is what you can do," and provide them with the options. "You can file a motion with the court. Does the other person agree? If the other person agrees that will be helpful. We don't have to go through the whole review process." You know, "We can just temporarily suspend it until this, until whatever time we think this is all going to be done." Those kinds of things where maybe there isn't something that the agency can do to snap our fingers and help someone, but we can point them in a direction that might be helpful for them.

Agency leadership and staff broadly considered their agency's efforts to "think outside of the box" and approach services in new ways as successful. By streamlining services, innovating on new procedures, and helping customers to become more aware of available options, staff and leadership perceived that they were able to facilitate service continuity and leverage opportunities to engage customers in new ways.

Agency leadership emphasized that these modified approaches to engaging customers helped catalyze another important change to service delivery already underway within some agencies, that is, changing the culture around how child support staff, and enforcement workers in particular, view and interact with NCPs. Experiencing the pandemic and the hardships imposed by its fallout collectively as a community, in the eyes of leaders, helped staff to be more understanding when customers were having a hard time meeting their obligations. As a result, staff often shared information on resources beyond child support to help address needs. Described a supervisor:

When you go through something like this, there's the understanding that, you know, these are hard times, and everybody's struggling, and things aren't normal... So knowing that particularly for enforcement, it was kind of like, "Well, should we be enforcing these cases?" "What are we supposed to be doing right now if we're not enforcing the cases?" And so, you know, wanting to be sure that to the extent that we could reach people, can we find out about what their circumstances are, right? What do they need? This is where the information about community resources became really important. 


\section{Implications for Service Accessibility}

Directors and staff highlighted a number of positive consequences for the ability of customers to access services that resulted from providing services in new ways. First, staff and directors noted that many customers experience barriers to engaging with child support services and court processes in-person, and new methods of interacting helped some customers overcome those barriers. Barriers to in-person services cited by staff and directors included lack of transportation or not having a driver's license; lack of child care; needing to take time off of work, particularly for indeterminately long court processes; mental health difficulties; and reluctance or anxiousness about going to court or appearing in the agency in-person. Commenting on higher show-rates for virtual hearings, one director described:

I think there's been better rates of appearance for court within virtual. I think because people, you know, if they're at work, if they have transportation issues, that becomes a non-barrier when you're appearing virtually ... you could essentially use a 15-minute break or a half-hour lunch or whatever to appear for court if you needed to. You can be wherever you happen to be to appear.

Virtual options expanded the ability of customers to receive the help or service that they needed and, as a result, helped agencies to increase cooperation from a group of customers they otherwise might have struggled to engage. Directors and staff also noted that for certain types of customers, virtual options were especially helpful, accessible, or safety-enhancing. First, they described that for custodial parents with young children, not having to attend processes in-person could make it much easier to access court processes. Described one director:

Especially with our paternity cases, I think our show rate has if anything improved... For people who have really young kids or multiple kids-and obviously if you're coming in for a paternity case, you've got young kids-it's just not realistic. They're not able to line up babysitters, so they bring kids in or they just don't show up because we tell them, "Don't bring your kids." So now, that barrier has disappeared a little bit, which is good.

Staff noted that virtual options can also be helpful when a participant lives far away and highlighted the usefulness of virtual options for customers with mental health issues, including anxiety. Described one staff member,

We had a fair share of people who had anxiety, especially being in a courtroom or being in a courthouse ... being able to just make that phone call and not have to show their face, because sometimes just even being in a public arena causes a level of anxiety, it has dropped.

Similarly, for victims of domestic violence, court processes provided the benefit of being able to take part in hearings from the safety and privacy of home. Noted one staff member, "I would say anyone with restraining orders or any domestic issues, they really enjoy the phone and Zoom. They don't have to come 
in and face that person... they can dial in a number. And they can sit in the comfort of their own home."

Staff noted that, particularly for tech-savvy and sometimes younger customers, accessing services virtually was often comfortable, familiar, and sometimes preferable. A supervisor described:

For people who are tech savvy, they love access to everything online. If you can go to the [agency] website, and you can click and download your review paperwork, if you can fill it out electronically and send it back, you can have that done much quicker, you don't have to come to the office. You know, if you're comfortable just calling and talking on the phone about a situation, and it's really not important to you to have that that face-to-face relationship, I mean, that can be really slick.

Staff noted that most customers had phones, and many had smartphones, particularly given that the demographic served by agencies is predominantly middleaged and younger. Directors and staff noted that their agencies had started collecting emails from customers more frequently, and with positive response, even in agencies that had encountered customer resistance to using email contact previously, the pandemic helped to shift customer willingness to engage via email.

Directors and staff also highlighted that some processes are particularly wellsuited for virtual interactions, such as completing and returning simple forms, getting a quick answer from a caseworker, or making payments. Accomplishing these actions virtually can help some customers move case processes forward more quickly. Described a director:

Texting, email, phone, all those things are a lot quicker than walking down here, driving down here, or whatever, waiting for a response. We'll be able to process through cases quicker, and that'll get them into court faster. And then mom, dad, whoever has custody of the child after the paternity is established can get money into that household quicker.

However, directors and staff also noted that virtual services do not work equally well for all customers, or across all service contexts. They noted that some customers need or prefer in-person interaction, due to language barriers, discomfort with technology, or simply personal preference for face-to-face interaction. Noted a director:

Some [customers] are very, "I want to be in person. I want to know what's going on. I want to be there and talk to you face to face." I would say a lot of the younger generation are all for Zoom and the phone. And I would say, you know, the older generation, they definitely want to talk face to face, have the letters and not rely so much on technology.

Other customers, particularly those in rural areas, sometimes had trouble accessing a reliable internet connection, particularly as libraries, and other public spaces in many communities, which customers might rely on for internet, had shut down due to the pandemic. Described one staff member: "A lot go to the 
library, and the libraries have been closed... They can't afford internet. They don't want to pay for internet. They don't have access to it."

Staff also noted that for certain types of services, in-person options are often preferable, and customer service experiences are likely to be of higher quality. For example, staff shared that when customers have a big change occurring on their case (such as a modification or a placement change), or when having a record of the action they took that day is especially important (such as having made a payment that the customer needs recorded), customers sometimes prefer to visit the agency in-person to accomplish the task. Further, actions that require notarization of paperwork are often easier for some customers to complete in person, because offices generally have notary services available onsite. Staff also highlighted the constraints of sharing information via email and issues related to confidentiality, as well as some customers' difficulty using email encryption. On the topic of court experiences, staff and directors were mixed; most felt that the quality of court processes was as high virtually as in person, whereas others felt that the virtual format reduced the opportunity to ask questions and engage with staff.

Despite these trade-offs, resoundingly, staff and directors across counties emphasized that having a broader array of options for customers and staff to communicate, including both in-person and virtual offerings, provided an opportunity to engage customers as broadly as possible. Most staff and directors expressed that they would not want services to be available online only; as human services providers, they felt maintaining in-office services was crucial for meeting their customer's needs. They also felt that offering services through a broader array of formats meant that they could be more responsive to the needs and interaction styles of their customers. Described one director:

That's why we wanted to offer a bunch of different options. To try to incentivize everybody to communicate with us, and work with us, and make it as easy as possible for them to get something back to us. Make a payment. All of those things are always on my radar. You know, like, this age group loves to text. We need to cater to them, because we're going to get higher participation in court, if they get a text back saying, "Oh, yup, I've got court." But some of our individuals have no smartphone, their track phone just ran out of money. They don't have their bicycle anymore, so they're walking here. It's really a wide gamut here of who we need to think about and keep in mind. And so, I think we've pretty much got it nailed in a good way to let everybody have options.

Directors and supervisors noted that having more virtual offerings was not without difficulties. Some noted the need to tailor letters and emails to include instructions specific to modality, and others emphasized the need for staff training and support on workflow and email management when they had more ways of interacting with customers available. Some felt it was harder to ensure services were provided at a high level of quality virtually relative to traditional offerings; some cautioned that while a broader array of offerings meant more opportunity to connect in the format of the customer's preference, it also meant workers needed to become aware of preferences and not default to providing the service in the format most convenient for staff. Summarized a supervisor: 
I think it is somewhere in between, depending on the person, right? Because I might think that the best way to deliver a service is over the phone. It might be easier; you know, it's faster, it's more efficient, I can answer all of the questions that they have. But if the other person is someone who retains information better when you're sitting across from them, who just wants more of that person to person relationship, or wants to be able to see the document I'm talking about, because that's just how they understand it better. That's been one of the struggles with all of this is that, you know, are we delivering the service? Yes, and I'm so grateful for the way we've been able to continue to deliver service. But, is it as meaningful to the person if it's not the way that they would normally receive it? I don't know. That's been one of the hard things. I think it depends on what the service is and it depends on how the person is used to receiving it.

\section{Lessons Learned}

Staff and directors reflected on the lessons they learned during the pandemic, and advice they would give to other agencies looking to the future. Across the board, directors and staff emphasized the importance of advance planning and considering a range of potential scenarios, with a goal of ensuring agency personnel have the support and information that they need. Several directors advocated for written, documented contingency plans for reference in a crisis. Such plans, they noted, might document the supplies, tools, and information needed in the face of a crisis; the roles and back-up roles played by all staff; and which staff must be physically present in a crisis. Staff emphasized that such advance planning is needed for a range of shortterm and longer-term crises, such as weather emergencies or security threats, at both the state and county levels. Elaborated one director:

Figure out your priorities. What do you need to accomplish? Have a contingency plan. Have the equipment; you know, don't wait until you come up for replacement for your equipment to get laptops and WebEx set up and Teams chat. Be ready, practice. We do a tornado drill; let's do a pandemic drill. Make sure that your mental muscle is ready. Make sure you have policies in place so that you can move quickly. Have an essential worker plan so that everybody knows, "You need to stay but you can go." Cover that when people accept positions, you know, make sure people know what they're buying on for.

Related to continency planning, staff and directors stressed the importance of ensuring that agencies have the technological infrastructure to continue to allow remote work to happen in a crisis; having a plan for distributing equipment to the people who need it; and ensuring that all staff know how to use it effectively. Directors emphasized the importance of working with county IT departments in advance of a crisis, to establish relationships and protocols, and ensuring that staff understand security and technology requirements in advance of offsite work. Similarly, leaders highlighted the importance of ensuring that staff understand what processes can be completed offsite, which must be completed within the 
agency, and providing staff with tools and resources to stay efficient and problem-solve when traditional methods of work are not available. Described one staff member, "I think the biggest one is taking stock of, what do you really have to do in your office and what can you really do from home? And, if you're going to perhaps have a mix of in the office or offsite time, you know, what are your people going to need from home? What are they going to need in the office?" Supervisors suggested creating lists reminding staff of the functions they are expected to perform when working offsite. They also recommended ensuring that staff are fully trained on processes such as e-filing in advance of needing to work remotely. Further, staff recommended providing forums for staff to provide feedback on how new processes are working and advised directors to be willing to listen and respond to staff input.

Finally, staff and directors stressed the importance of having clear communication plans for customers and staff. Suggestions included communication for customers about how to best reach staff when in-office options are not available; how to complete processes via email and web; information on the closure status of agencies; and precautions in place for those visiting the office in person. For staff, study participants suggested having clear plans in place that ensure staff know how to communicate, the tools available for communication, and expectations for staying in touch with colleagues and supervisors. Described one staff member:

Equipment wise, make sure everyone has what they need to work from home. And, build that communication and just make sure everyone is on the same track for everything. And then, I guess really making sure that the customers know how to access or reach you, maybe like an information card or something as to, your email and your website, and things you can and can't do virtually. Like a "how to"-how we're going to do this and what services we're going to do virtually versus what services you have to come in for.

\section{Expectations for the Future}

The child support agencies included in this study had enacted several process changes in the course of the pandemic that they hoped would persist in the future. These included streamlined administrative processes, such as new ways of processing paperwork, as well as innovative new court-related processes, such as pre-court meetings and hearings that act as alternatives to contempt. Staff also noted that they hoped enhanced outreach efforts and gains in understanding of customer circumstances among workers would persist into the future.

From the perspective of virtual service offerings, broadly, agencies acknowledged that virtual ways of interacting were increasingly ubiquitous across many aspects of society and would likely continue to grow as child support agencies continue to modernize. Noted one director, "I think customers are probably also learning how to use different virtual platforms and technology themselves. So, I think over time, it's going to be a lot easier. And I think you're going to see more people want to communicate that way." A supervisor added: 
We should have a child support app. "Click to pay your child support." You know, how do you do that? It seems like there's an app for everything, right? You can transfer money in Venmo or wherever... if you can quick send a payment through and it'll hit your child support account, and show, you know, there's not fees, it's just easy... When you think about technology and the possibilities of what could be available virtually, there's a lot of potential. I think if the policies, and all of the paperwork, and some of those things could catch up, I think it would work a lot better than what it's currently designed for.

Some staff noted that email communication with customers would likely persist; staff and leadership from several agencies expressed interest in pursuing texting options and video conferencing options for customers. Agencies that enhanced or built websites found the improvements beneficial and expected to continue supporting them. Agencies had mixed impressions of whether court hearings would remain virtual by default or as an accessibility option.

Regarding virtual work arrangements, agencies were mixed in their future plans. No agencies expressed an expectation or desire to have staff work remotely full time or give up a physical office space entirely; agency staff and leadership emphasized that from a pragmatic standpoint, many processes still required a physical presence in an office at least some of the time, and from a cultural standpoint, they felt it was important to spend time with each other and be available to customers in person. Summarized one director, "We're a resource agency. And we can't be resourceful if we're not there to be able to do it." A supervisor concurred, elaborating:

I think in the olden days of casework where a lot of it really was paper pushing and there really wasn't a lot of interaction, [being fully virtual] might've been okay, you know, if you had people in the office to send stuff out in the mail. But I feel like the way that we're trying to move towards in terms of customer service, being more customer service focused, that you really need, as a customer, a place they can go and talk to someone... They want to go into a place and get the payment coupon, or get the review paperwork, so that they can leave having that document that they want. It's that kind of like sense of security of like, "I went there, I did the thing and now I'm done." If you were 100 percent remote, you know, how do you offer that to someone?

Leadership within several agencies felt that hybrid schedules, with staff in the office most days but having the option to work at home several days each week, were likely to persist, given positive experiences, staff preferences, and benefits for staff morale; these agencies sought to maintain the benefits afforded to staff by offering periodic virtual work, while also providing opportunities for staff to engage with each other and build camaraderie in person. Regardless of whether they expected regular remote options for staff, however, directors generally noted that having the equipment to work remotely provided agencies with helpful flexibility for intermittent remote work options in the future; for example, having remote options allows staff to continue working and providing services despite inclement weather or a staff injury or illness. 
As agencies looked to the future of virtual service delivery, they identified several areas in which additional guidance and resource are needed to support their abilities to offer services through multiple modalities. Agency leadership expressed concern about performance measures and implications for future funding, particularly given local variation in remote work capabilities during the pandemic. Most directors acknowledged that their collections had fallen during the pandemic and noted that timelines were more difficult to achieve and desired more information from federal and state partners about the implications. Agency leadership and staff also expressed a need for additional guidance around data safeguards, information technology security, and specifically the steps they needed to take to ensure that staff are in compliance with federal regulations when working remotely. Directors in particular were aware of the potential of an IRS audit and sought information that would help their agency proactively avoid being noncompliant. Described one director:

At some point we're not going to have that excuse where, "Well, gee, it's COVID and we're letting things slide a little bit." You know, we're going to have to comply, so we need to know how we can safely and securely work from home... And we need to know how we can do that. I mean you have to know, is the IRS going to knock on your door for an audit?

\section{Discussion and Conclusions}

The COVID-19 pandemic upended many aspects of life and work. For child support agencies, entities that typically relied on in-office procedures to provide services that families count on, the pandemic forced rapid and dramatic changes to operations and service provision. These interviews suggest that child support agencies experienced the pandemic differently, given local and agency-specific context. County child support agencies experienced different levels of input from local administrators, which shaped the decisions agency leaders made within their respective agencies. Further, local conditions, such as infection rates and outbreaks, differed across time and counties. Decision-making about what was safe and appropriate for customers and staff therefore differed across time and local contexts. Additionally, these findings highlight the particular challenges faced by smaller, rural counties in times of crises that make face-to-face interactions difficult. This study found that broadband access issues introduced challenges for staff as they worked to keep their agencies operating, as well as customers in accessing essential services. Findings from this study indicate that the agencies that took part in these interviews experienced numerous successes as they navigated these new waters, despite variation in their experiences.

Consistent with other research on child support agency adaptations in the pandemic (The Future of Child Support, 2020), though not without challenges and adaptations, they were ultimately able to continue providing most services. Adaptability and openness to change on the part of agency leadership and staff; creativity and flexibility in developing innovative solutions to complex problems; and dedicating effort to communication and collaboration helped agencies to provide service continuity. Adaptations were also made possible thanks to leadership and staff's 
dedication to supporting each other and their customers during an exceptionally difficult period.

Also consistent with prior work, participants in this study identified areas of promise, and optimism for the value offering services through virtual modalities could provide customers and staff (The Future of Child Support, 2020). Consistent with evidence from other human services providers within and beyond the context of the pandemic, participants in this study identified that virtual offerings can help reduce barriers to in-person service engagement for many (Alford et al., 2019; Benton et al., 2021a, 2021c; Hetling et al., 2014; Lenhart et al., 2005), and in particular, customers vulnerable to exclusion from the economy and other systems due to challenges such as transportation barriers, mental health struggles, and lack of child care (Hirko et al., 2020; National Home Visiting Resource Center, 2017; Nilson, 2017; SemanchinJones, 2011). However, findings from this study are also consistent with prior evidence that indicates that virtual offerings alone are inadequate for meeting the needs of all customers (Benton et al., 2021a). Just as in-person services alone introduce access barriers for some vulnerable groups, services offered exclusively through virtual modalities could limit access for customers such as those with internet access barriers, language barriers, technology limitations, and disabilities (Benton et al., 2021c).

\section{Implications for Policy, Practice, and Research}

The interviews conducted for this analysis suggest several steps for further consideration broadly across human service providers and areas for future exploration. First, findings from these interviews suggest that human services agencies' use broader array of communication modalities with customers, including more traditional strategies and newer, technology-facilitated approaches, can help to provide agencies with the opportunity to engage with as broad a customer base as possible. These interviews highlight that customers, their needs, and the tasks they seek to accomplish are different, and therefore, providing staff with a broad array of tools that best helps to "meet the customer where they are" represents an opportunity to expand the agency's reach. To the extent that agencies continue to explore options for making services and information accessible through multiple methods, and streamlining and reducing administrative requirements, these opportunities will only continue to grow. Given that many states use centralized data systems to facilitate work, as well as the constrained resources many local human services providers have available to operate with, state governments could help support local efforts by continuing to modernize state systems and tools; making more services and functions electronically accessible to workers and customers; providing localities with resources and incentives to implement creative new approaches; providing forums for localities within a state to share information about successes and challenges with each other; and, when possible, procuring technological services and resources that agencies could access at a lower cost than they might be able to independently. Future research could examine the evolution of these strategies in the years to come. 
Additionally, and consistent with previous research (Vogel, 2021), a key finding that emerged from this work is that proactive outreach from agencies to customers, even when nonpayment has yet to become an issue, can help build relationships and identify customer needs. The pandemic provided opportunities for staff to strengthen outreach efforts, allowing staff to help customers obtain the information and support that they needed, and helping facilitate transitions towards customer-focused, supportive approaches to service delivery. Continuing to expand upon gains will require sufficient staff capacity moving forward, as well as leadership directives on expectations.

Next, regarding staff work arrangements, findings from these interviews suggest there is no one-size-fits-all approach to moving forward that will meet the needs of all agencies. Given the current technological and process environment that child support agencies function within, some tasks and functions will likely need to continue to be performed in-person for the foreseeable future. However, whether agencies choose to make hybrid virtual and in-person work arrangements regularly available to staff, or only to allow them on an intermittent, asneeded basis (for example, during a weather event), having the infrastructure and resources in place to facilitate remote work grants agencies considerable flexibility. Agencies have made substantial gains in such infrastructure and processes throughout the pandemic; building on and institutionalizing these successes will help them to carry forward into the future. State and federal agencies can help ensure localities work within required parameters by developing user-friendly guidance and resources related to confidentiality and security. Further, given variation in local contexts and resources, to the extent that federal and state agencies can facilitate information-sharing across county agencies and identify ways to help county agencies address resource and technology gaps, these actions could help to mitigate inequities and facilitate greater consistency in service. Future research efforts could examine how staff work arrangements continue to evolve post-pandemic.

Next, findings indicate a need for contingency planning across a broad array of scenarios, as well as infrastructure to help mitigate future crises. State and county agencies have acquired invaluable experience and information about how to adapt in the face of the pandemic. Continuing these efforts forward by assessing for future short-term and long-term threats, making plans for staffing and resources, and coordinating across county agencies and with the state is worthy of consideration across levels of government. Findings also underscore the need to build relationships with key partners, such as IT providers and health departments, prior to crises.

Finally, a crucial theme that emerged from these interviews is the need for investment in broadband. Difficulty accessing broadband places low-income customers, and those in rural areas, at a disadvantage for obtaining essential services and limits the capability of staff to perform essential duties from off-site locations. The pandemic has helped to expose the considerable inequity in broadband access across many domains, from school to work to participation in social services. Solving this problem cannot fall to state or county administrators of human services agencies alone. It will require collaboration across levels of government and public and private sectors. 


\section{Limitations}

While findings from these interviews provide insight into child support agency adaptations and potential areas for future consideration, the analysis has several important limitations. These data were collected at a specific point-in-time (Winter of 2021), and conditions have quickly changed since data collection occurred. Additionally, the study was conducted in just five of Wisconsin's 72 counties, with child support agencies exclusively. Other agencies and administrators within counties in which these agencies were located were not interviewed, nor were customers of child support agencies. The agencies and staff that participated in interviews are not representative of all child support agencies or staff other human services providers more broadly. While some consistent themes, and therefore implications, emerged, they are based on a small and nonrepresentative sample. Future studies could draw on these findings as a starting point to gather data from a broader pool of county stakeholders, or a broader array of county and state child support agencies to provide a more complete picture of agency experiences.

Funding The research reported in this paper was supported by the Child Support Research Agreement between the Wisconsin Department of Children and Families and the Institute for Research on Poverty at the University of Wisconsin-Madison.

Availability of Data and Material Data used in this paper draw from interviews conducted with respondents for whom confidentiality was promised during the informed consent process, under the purview of the UW-Madison Institutional Review Board. Therefore, data are not publicly available.

Code Availability Not applicable.

\section{Declarations}

Conflict of Interest/Competing Interests The authors declare no competing interests.

\section{References}

Alford, K. A., Denby, R. W., \& Gomez, E. (2019). Use of smartphone technology in foster care to build relational competence: Voices of caregivers and implications for prudent parenting. Journal of Family Social Work, 22(3), 209-230.

Andersson, G., Thompson, E., \& Duntava, A. (2017). Life-table representations of family dynamics in the 21st century. Demographic Research, 37, 1081-1230.

Bambling, M., King, R., Reid, W., \& Wegner, K. (2008). Online counselling: The experience of counsellors providing synchronous single-session counselling to young people. Counselling and Psychotherapy Research, 8(2), 110-116.

Bartfeld, J., \& Meyer, D. R. (2003). Child support compliance among discretionary and nondiscretionary obligors. Social Service Review, 77(3), 347-372.

Benton, A., Tschantz, J., Vandenberg, A., Waters, A., \& Winston, P. (2021a). Perspectives of program participants on virtual human services during COVID-19. Office of the Assistant Secretary for Planning and Evaluation, U.S. Department of Health and Human Services. Washington, D.C. 
Benton, A., Tschantz, J., Vandenberg, A., Waters, A., \& Winston, P. (2021b). Easy or hard? Delivering different types of services virtually. Office of the Assistant Secretary for Planning and Evaluation, U.S. Department of Health and Human Services. Washington, D.C.

Benton, A., Tschantz, J., Vandenberg, A., Waters, A., \& Winston, P. (2021c). Virtual services for different populations. Office of the Assistant Secretary for Planning and Evaluation, U.S. Department of Health and Human Services. Washington, D.C.

Bigelow, K. M., Carta, J. J., \& Burke Lefever, J. (2008). Txt u ltr: Using cellular phone technology to enhance a parenting intervention for families at risk for neglect. Child Maltreatment, 13(4), 362-367.

Braun, V., \& Clarke, V. (2006). Using thematic analysis in psychology. Qualitative Research in Psychology, 3(2), 77-101.

Brito, T. L. (2012). Fathers behind bars: Rethinking child support policy toward low-income noncustodial fathers and their families. Journal of Gender Race \& Justice, 15, 617.

Chen, Y., \& Meyer, D. R. (2017). Does joint legal custody increase child support for nonmarital children? Children and Youth Services Review, 79, 547-557.

Committee on Ways and Means, U.S. House of Representatives. (2018). 2018 Green book: Background material and data on the programs within the jurisdiction of the committee on ways and means (24th ed.). U.S. Government Printing Office.

Conroy, T., Deller, S., Kures, M., Low, S., Glazer, J., Huyke, G., \& Stark, C. (2021). Broadband and the Wisconsin economy. Study Series No. 7. University of Wisconsin Extension: Madison, WI. Accessed August 6, 2021: https://economicdevelopment.extension.wisc.edu/files/2021/01/2021-01-07-Broadband-Report. pdf

Cook, S. T. (2012). Child support enforcement use of contempt and criminal nonsupport charges in Wisconsin. CSPR-09-11-T7B. University of Wisconsin-Madison, Institute for Research on Poverty.

Cook, J. E., \& Doyle, C. (2002). Working alliance in online therapy as compared to face-to-face therapy: Preliminary results. CyberPsychology \& Behavior, 5(2), 95-105.

Cook, S., \& Noyes, J. L. (2011). The use of civil contempt and criminal nonsupport as child support enforcement tools: A report on local perspectives and the availability of data. University of Wisconsin-Madison.

Crabtree, B., \& Miller, W. (1999). A template approach to text analysis: Developing and using codebooks. In Crabtree, B., Miller, W. (Eds.), Doing Qualitative Research (pp. 163-177.) Newbury Park, CA: Sage.

Cruden, G., Campbell, M., \& Saldana, L. (2021). Impact of COVID-19 on service delivery for an evidence-based behavioral treatment for families involved in the child welfare system. Journal of Substance Abuse Treatment, 108388.

Cuesta, L., \& Meyer, D. R. (2018). Child poverty and child support policy: A comparative analysis of Colombia and the United States. Children and Youth Services Review, 93, 143-153.

Emezue, C. (2020). Digital or digitally delivered responses to domestic and intimate partner violence during COVID-19. JMIR Public Health and Surveillance, 6(3), e19831.

Fereday, J., \& Muir-Cochrane, E. (2006). Demonstrating rigor using thematic analysis: A hybrid approach of inductive and deductive coding and theme development. International Journal of Qualitative Methods, 5(1), 80-92.

Finn, J., Kerman, B., \& LeCornec, J. (2004). Building skills-building futures: Providing information technology to foster families. Families in Society, 85(2), 165-176.

Finn, J., \& Schoech, D. (2008). Internet-delivered therapeutic interventions in human services: Methods, issues, and evaluation. Journal of Technology and Human Services, 26 (2/3/4). Philadelphia, PA: Haworth Press.

Fogler, J. M., Normand, S., O’Dea, N., Mautone, J. A., Featherston, M., Power, T. J., \& Nissley-Tsiopinis, J. (2020). Implementing group parent training in telepsychology: Lessons learned during the COVID-19 pandemic. Journal of Pediatric Psychology, 45(9), 983-989. Accessed August 6, 2021: https://doi.org/ 10.1093/jpepsy/jsaa085

Font, S. A. (2021). What lessons can the child welfare system take from the COVID-19 pandemic? American Enterprise Institute. Accessed August 6, 2021: https://www.aei.org/research-products/report/ what-lessons-can-the-child-welfare-system-take-from-the-covid-19-pandemic/

Franklin, C., \& Ballan, M. (2001). Reliability and validity in qualitative research. The Handbook of Social Work Research Methods, 4, 273-292. 
Gentry, J. (2019). Child support enforcement program, (Informational Paper No. 42). Wisconsin Legislative Fiscal Bureau. Accessed August 6, 2021: https://docs.legis.wisconsin.gov/misc/lfb/informational_ papers/january_2017/0042_child_support_enforcement_program_informational_paper_42.pdf

Goldberg, J. S. (2015). Coparenting and nonresident fathers' monetary contributions to their children. Journal of Marriage and Family, 77(3), 612-627.

Ha, Y., Cancian, M., \& Meyer, D. R. (2018). Child support and income inequality. Poverty \& Public Policy, 10(2), 147-158.

Hah, H., \& Goldin, D. (2019). Exploring care providers' perceptions and current use of telehealth technology at work, in daily life, and in education: Qualitative and quantitative study. JMIR Medical Education, 5(1), e13350. Accessed August 6, 2021: https://doi.org/10.2196/13350

Hetling, A., Watson, S., \& Horgan, M. (2014). "We live in a technological era, whether you like it or not" client perspectives and online welfare applications. Administration \& Society, 46(5), 519-547.

Hirko, K., Kerver, J., Ford, S., Szafranski, C., Beckett, J., Kitchen, C., \& Wendling, A. (2020). Telehealth in response to the COVID-19 pandemic: Implications for rural health disparities. Journal of the American Medical Informatics Association, 27(11), 1816-1818. Accessed August 6, 2021: https:// doi.org/10.1093/jamia/ocaa156

Hodges, L., \& Vogel, L. K. (2020). Too much, too little, or just right? Recent changes to state child support guidelines for low-income noncustodial parents. Journal of Policy Practice and Research, $1-32$.

Husebø, A. M. L., \& Storm, M. (2014). Virtual visits in home health care for older adults. The Scientific World Journal, 2014, 1-11. Accessed August 6, 2021: https://doi.org/10.1155/2014/689873

Internal Revenue Service. U.S. Department of the Treasury. (2021). Publication 1075: Tax information security guidelines for federal, state and local agencies. (Cat. No. 46937O). Washington, DC: U.S. Government Publishing Office. Accessed January 9, 2022: https://www.irs.gov/pub/irs-pdf/p1075. pdf

Johns Hopkins University \& Medicine. (2022). Coronavirus Resource Center. Accessed February 14, 2022: https://coronavirus.jhu.edu/us-map

Jones M., \& Ewald, M. (2017, May 17). Putting rural Wisconsin on the map. WisContext. Accessed August 6, 2021: https://www.wiscontext.org/putting-rural-wisconsin-map

Kelso, G. L., Fiechtl, B. J., Olsen, S. T., \& Rule, S. (2009). The feasibility of virtual home visits to provide early intervention: A pilot study. Infants \& Young Children, 22(4), 332-340.

Knapp, D. (2021). The COVID Economy: The economic impacts of COVID-19 in Wisconsin. Forward Analytics: Wisconsin. Accessed August 6, 2021: https://www.forward-analytics.net/wp-content/ uploads/2021/01/2021-FA-Report-Final-Covid-and-the-Economy.pdf

Knapp, D. \& Votava, J. (2020). Broadband in rural Wisconsin: Identifying gaps, highlighting successes. Forward Analytics: Wisconsin. Accessed August 6, 2021: https://www.forward-analytics.net/wpcontent/uploads/2020/11/2020-FA-Report-Broadband-in-Rural-Wisconsin.pdf

Lenhart, A., Madden, M., \& Hitlin, P. (2005). Teens and technology: Youth are leading the transition to a fully wired and mobile nation. Pew Internet \& American Life Project.

Mishna, F., Milne, E., Bogo, M., \& Pereira, L. F. (2020). Responding to COVID-19: New trends in social workers' use of information and communication technology. Clinical Social Work Journal, 1-11.

Mogil, C., Hajal, N., Garcia, E., Kiff, C., Paley, B., Milburn, N., \& Lester, P. (2015). FOCUS for early childhood: A virtual home visiting program for military families with young children. Contemporary Family Therapy, 37(3), 199-208.

National Home Visiting Resource Center. (2017). Technology in home visiting: Strengthening service delivery and professional development using virtual tools. Innovation Roundup Brief.

Nepomnyaschy, L., \& Garfinkel, I. (2010). Child support enforcement and fathers' contributions to their nonmarital children. Social Service Review, 84(3), 341-380.

Newman, L., Bidargaddi, N., \& Schrader, G. (2016). Service providers' experiences of using a telehealth network 12 months after digitisation of a large Australian rural mental health service. International Journal of Medical Informatics, 94, 8-20. Accessed August 6, 2021: https://doi.org/10.1016/j.ijmedinf.2016. 05.006

Nilson, C. (2017). Collaborative risk-driven intervention: Research supporting technology-enabled opportunities for upstream virtual services in rural and remote communities. Journal of Community Safety and Well-Being, 2(3), 76-86.

Nowell, L. S., Norris, J. M., White, D. E., \& Moules, N. J. (2017). Thematic analysis: Striving to meet the trustworthiness criteria. International Journal of Qualitative Methods, 16(1), 
Oehme, K., O'Rourke, K. S., \& Bradley, L. (2021). Online virtual supervised visitation during the COVID-19 pandemic: One state's experience. Family Court Review, 59(1), 131-143.

Office of Child Support Enforcement, Administration for Children and Families, U.S. Department of Health and Human Services. (2009). Use of electronic signatures on applications for IV-D services. Accessed January 9, 2022:https://www.acf.hhs.gov/css/policy-guidance/use-electronic-signaturesapplications-iv-d-services

Office of Child Support Enforcement, Administration for Children and Families, U.S. Department of Health and Human Services. (2020a). Fiscal year 2019 preliminary report. Accessed August 6, 2021: https://www.acf.hhs.gov/css/resource/fy-2019-preliminary-data-report

Office of Child Support Enforcement, Administration for Children and Families, U.S. Department of Health and Human Services (2020b). COVID-19: Frequently asked questions for child support programs. Accessed August 6, 2021:https://www.acf.hhs.gov/css/covid-19-faqs-child-support-programs

Office of Regional Operations, Administration for Children and Families, U.S. Department of Health and Human Services. (2020). ACF program flexibilities on IT and PPE to support state, local and tribal human services workforce during COVID-19 response. Accessed January 9, 2022:https://www.acf. hhs.gov/sites/default/files/documents/oro/acf_program_flexibilities_it_ppe.pdf

Reddick, C. G., Enriquez, R., Harris, R. J., \& Sharma, B. (2020). Determinants of broadband access and affordability: An analysis of a community survey on the digital divide. Cities, 106, 102904.

Rosen, C. S., Morland, L. A., Glassman, L. H., Marx, B. P., Weaver, K., Smith, C. A., Pollack, S., \& Schnurr, P. P. (2021). Virtual mental health care in the Veterans Health Administration's immediate response to coronavirus disease-19. American Psychologist, 76(1), 26-38. Accessed August 6, 2021: https://doi.org/10.1037/amp0000751

Schreier, M. (2012). Qualitative content analysis in practice. Sage.

Semanchin-Jones, A. (2011). Virtual visitation and child welfare. CW 360: Child Welfare and Technology. St. Paul, MN: Center for Advanced Studies in Child Welfare, School of Social Work, University of Minnesota. Accessed August 6, 2021: https://cascw.umn.edu/wpcontent/uploads/2013/12/ CW360_2011.pdf

Snell, E. K., Wasik, B. A., \& Hindman, A. H. (2020). Using texting to help families build their children's vocabulary at home. The Reading Teacher, 74(1), 49-57.

Sorensen, E. (2010). Child support plays an increasingly important role for poor custodial families. Urban Institute.

Supreme Court of Wisconsin. (2020a). In Re: The matter of remote hearings during the COVID-19 pandemic. Accessed August 6, 2021: https://dcf.wisconsin.gov/files/press/2020a/videoconferencingorder-covid.pdf

Supreme Court of Wisconsin. (2020b). Wisconsin Legislature, Petitioner, v. Secretary-Designee Andrea Palm, Julie Willems Van Dijk and Lisa Olson, In Their Official Capacities As Executives of Wisconsin Department of Health Services, Respondents. 2020bAP765-OA. Accessed August 6, 2021: https://www.wicourts.gov/sc/opinion/DisplayDocument.pdf?content=pdf \&seqNo=260868

Supreme Court of Wisconsin. (2020c). In Re: The matter of the extension of orders and interim rule concerning continuation of jury trials, suspension of statutory deadlines for non-criminal jury trials, and remote hearings during the COVID-19 pandemic. Accessed August 6, 2021: https://www.wicourts. gov/news/docs/jurytrials2.pdf

The Future of Child Support [White Paper]. (2020). Insights.conduent.com; Conduent. Accessed May 3, 2021: https://insights.conduent.com/white-papers/white-paper-the-future-of-child-support

U.S. Census Bureau. (2021). Quick facts. Accessed August 6, 2021: https://www.census.gov/quickfacts/ fact/table/US/PST045219

Vaismoradi, M., Turunen, H., \& Bondas, T. (2013). Content analysis and thematic analysis: Implications for conducting a qualitative descriptive study. Nursing \& Health Sciences, 15(3), 398-405.

Vogel, L. K. (2020a). Help me help you: Identifying and addressing barriers to child support compliance. Children and Youth Services Review, 110, 104763.

Vogel, L. K. (2020b). Barriers to meeting formal child support obligations: Noncustodial father perspectives. Children and Youth Services Review, 110, 104764.

Vogel, L. K. (2021). The right tool for the job: Child support enforcement tools and their relationship to payments. Human Service Organizations: Management, Leadership \& Governance.

Wisconsin Department of Children and Families. (2021a). Overview of child support services for parents. Accessed August 6, 2021: https://dcf.wisconsin.gov/cs/overview

Wisconsin Department of Children and Families. (2021b). Reviewing a court order for a change. Accessed August 6, 2021: https://dcf.wisconsin.gov/cs/review 
Wisconsin Department of Children and Families. (2021c). Enforcing child support orders. Accessed August 6, 2021: https://dcf.wisconsin.gov/cs/enforce/home

Wisconsin Department of Children and Families. (2021d). Calendar year 2021d preliminary child support allocations. Division of Family and Economic Security Administrator's Memo Series, 20-05. Accessed February 28, 2022: https://dcf.wisconsin.gov/files/w2/admin-memos/pdf/20-05attachment1. pdf

Wisconsin Department of Health Services. (2020a). Executive order \#72: Relating to a proclamation declaring a health emergency in response to the COVID-19 coronavirus. Accessed August 6, 2021: https://evers.wi.gov/Documents/EO/EO072-DeclaringHealthEmergencyCOVID-19.pdf

Wisconsin Department of Health Services. (2020b). Order for statewide school closure. Accessed August 6, 2021: https://evers.wi.gov/Documents/EO/SignedSchoolClosure.pdf

Wisconsin Department of Health Services. (2020c). Emergency order \#12: Safer at home order. Accessed August 6, 2021: https://evers.wi.gov/Documents/COVID19/EMO12-SaferAtHome.pdf

Wisconsin Department of Health Services. (2021). DHS adds "critically high" category to disease activity dashboard showing impact of COVID-19. Accessed August 6, 2021: https://www.dhs.wisconsin.gov/ news/releases/111120.htm

Wisconsin Department of Workforce Development. (2020). Wisconsin's economy and workforce in 2020. Accessed August 6, 2021: https://jobcenterofwisconsin.com/wisconomy/wits_info/downloads/OEA/ 2020/WisconsinEconomyandWorkforce2020.pdf

World Health Organization. (2020). WHO Director-General's opening remarks at the media briefing on COVID-19. 11 March 2020. Accessed August 6, 2021: https://www.who.int/director-general/speeches/ detail/who-director-general-s-opening-remarks-at-the-media-briefing-on-covid-19---11-march-2020

Zack, J. S. (2008). How sturdy is that digital couch? Legal considerations for mental health professionals who deliver clinical services via the Internet. Journal of Technology in Human Services, 26, 226-252.

Publisher's Note Springer Nature remains neutral with regard to jurisdictional claims in published maps and institutional affiliations. 